\title{
Indoor Air Pollution and Health Risks among Rural Dwellers in Odeda Area, South-Western Nigeria 1Oguntoke, 0.; ${ }^{2}$ Opeolu B O. and ${ }^{3}$ Babatunde N.
}

\begin{abstract}
This study monitored the concentration of five greenhouse gases and examined the health outcome among the exposed rural residents. A total of 15 villages were randomly selected from the list of villages without electricity supply in Odeda local government area, Ogun State (southwestern Nigeria). Gasman auto sampler was used to monitor indoor air quality in houses selected through systematic random sampling. Air monitoring was observed in replicates over a period of three months. In order to elicit information on energy utilization and occurrence of air pollution related health problems among the rural dwellers, one questionnaire was administered to a male or female household head in each selected house. Due to absence of reliable health records in the area, recall method was used collect information on the health problems treated and or experienced by village dwellers. The mean values of $\mathrm{SO}_{2}, \mathrm{NO}_{2}, \mathrm{CO}, \mathrm{H}_{2} \mathrm{~S}$ and $\mathrm{CH}_{4}$ are $0.05 \pm 0.005,0.21 \pm 0.013$, $82.5 \pm 1.98,0.15 \pm 0.009$ and $0.15 \pm 0.01$ among the fifteen villages. Although there were no significant variations in the concentration of these gases among the villages, they were all above the recommended National Ambient Air standards. The trend of indoor air pollution may not be unconnected with 83.3 percent of the residents depending on fuel-wood for energy supply. Overall, more than one-quarter of the residents cook within their dwelling units. Prevalent health problems among the residents included sneezing (44\%), nausea (34\%), headache (34\%), dizziness (31.1\%), eye irritation (23.3\%), and catarrh (24\%) among others. These health problems are largely consequences of human exposure to high concentration of gaseous pollutants in the air. Intervention to control rural indoor air pollution requires urgent attention so as to preserve the health of teeming rural inhabitants and safeguard the overall environment.
\end{abstract}

Key words: Indoor environment, air quality, rural health, fuel-wood

\section{Introduction}

$\mathrm{A}_{\text {described as an urban problem }}$ globally. Although true, this assertion tends to gloss over the variation in the dimension of air pollution problem in the rural areas. As dangerous as polluted outdoor air can be to human health, indoor air pollution actually poses a greater health risk on a global level. About 2.8 million deaths per year results from breathing elevated levels of indoor smoke from dirty fuel. Although many people associate air pollution with outdoor urban environment, some of the highest concentrations actually occur in rural areas. Hence, rural dwellers are exposed to the risks associated with pollutants from smoke emitted from burning unprocessed biomass fuels (Sinton and Weller, 2003; Mac, 2009; Theuri, 2009).

By far the greatest threat of indoor air pollution occurs in the developing countries of the world, where some 3.5 billion people mostly in rural areas continue to rely on traditional fuel for cooking and heating. According to a World Bank report, indoor air pollution in developing countries is designated as one of the four most critical global environmental problems (Carter, 1998; Mac, 2009). Burning biomass fuel indoor is a major source of large amounts of smoke and other pollutants in the confined space of the home, thereby providing a perfect avenue for human exposure. Lipid and gaseous fuels such as kerosene and bottled gas, although not completely pollution free, are many times less polluting than unprocessed solid fuels.

In South Africa for instance, approximately 60 percent of the population relies on low quality coal as the primary household energy source. Furthermore, in majority of the household using traditional (fuel wood) and transitional fuels (coal), the combustion processes are inefficient, resulting in high level of pollutants and the poorly vented stoves cause the release of these pollutants into the indoor environment. The popular gaseous, liquid and solid substances emitted into the environment are suspended particulates, carbon monoxide, hydrocarbons, nitrogen oxides, sulphur oxides, ozone and lead. All these pollutants that are found along with carbon dioxide in biomass smoke have been identified as mutagenic compounds while some others are carcinogenic (WHO, 1997). Field test on wood burning stove and furnace reported elevated levels of $\mathrm{CO}, \mathrm{NO}, \mathrm{NO}_{2}$, and $\mathrm{SO}_{2}$ during the appliance operation (Traynor, et al., 1985; Knight, et al., 1985) and particulate matters (Moschandreas, et al., 1981). A major source of these gases is linked to burning of coal, firewood and agricultural 
residues apart from emission from fossil-fuel combustion, cigarette smoke, heaters and boilers among others. Indoor concentration of these contaminants is significant indoors than in the ambient environment considering the exposure duration (Smith, 2009).

Indoor air pollution has diverse effects on people that are exposed, depending on body constitution, lifestyle, nutritional status and age. Generally speaking, older people and children are more sensitive to air pollutants (Jones, 1999). Studies have shown that women and children, who are the most exposed and vulnerable to the pollutants, are two to six times at risk of contracting serious respiratory infections (WHO, 1997). Epidemiological studies in developing countries have linked exposure to indoor air pollution from dirty (biomass) fuel to acute respiratory infection (ARI) in children; chronic obstructive lung diseases such as asthma and chronic bronchitis; lung cancer; and still-births and other related problems. Other health problems are irritation of the skin, eyes, nose and throat; dizziness, nausea and long-term chronic health effects (Ayars, 1997). According to Traynor et al., (1985), long time exposure to biomass combustion results in chronic obstructive lung diseases, heart diseases, acute respiratory infections, low birth weight, eye disorder, conjunctivitis, blindness and cancer. Specifically, children carried on their mothers' back as they cook using smoky stoves contracted pneumococcal infections 2.5 times higher than non-exposed ones (WHO, 1997; Mac, 2009). Several studies found strong links between chronic lung diseases in women and exposure to smoke from open cook stoves (Moschandreas, et al., 1981), due to high concentration of $\mathrm{NO}_{2}$ (Frampton, et al., 1991; Goldstein, et al., 1988 and Jones, 1999) and $\mathrm{SO}_{2}$ (Oin, et al., 1993).

This paper therefore assessed indoor air quality in selected villages in order to ascertain the level of some gases and the relationship between indoor air quality and the prevalent health problems among the village dwellers. Information on indoor air quality in rural communities is particularly scarce in Nigeria, while research effort to reveal the possible health implication of high concentration of pollutant gases on the rural residents' is limited to speculations.

\section{The Study Area}

Odeda Local Government area with headquarters at Odeda, is one of the 20 local government areas in Ogun State, southwest Nigeria. It lies on the North-eastern zone of the State, on Longitude $7^{0} 31^{1}$ to $7^{0} 32^{1}$ and Latitude $3^{0} 32^{1}$ and $3^{0} 62^{1}$. The local government area, shares boundary with Abeokuta south local government area, Obafemi-Owode local government area and Oyo state. The approximate population size is put at 19,819 (1991 population census) and a land area of 97,298.34 hectares.

The mean monthly rainfall and temperature of the area are about $900.3 \mathrm{~mm}$ and $33.3^{\circ} \mathrm{C}$ (Akani, 1992). Odeda LGA falls largely within the derived savanna vegetation which dominated the northernmost part of Ogun state. Nevertheless, pockets of forest vegetation which have not been degraded by human activities still exist. Hence, the floristic composition includes both true forest and savanna species. Important tree species found in this vegetation type include Lophira lanceslate, Daniellia oliverri and Afzolia africana (Gbadegesin, 1992) among others.

Odeda LGA is predominantly a rural community with numerous villages spread across the land area. Farming is the major occupation of the residents. Others occupations are trading in farm produce, which is done on the periodic market days and hunting.

\section{Research Methodology}

A multi-stage sampling procedure was employed to select the study villages. Firstly, 15 villages were randomly selected from the list of villages in Odeda LGA after excluding villages with electricity supply, tarred roads and other modern facilities. The aim is to target villages that depend largely on fuel wood for energy supply. The names of the villages are Aaya, Arowo, Gbagba, Kinleyin, Osara, Kemta Apakila, Ogboja, Alli-Iwo, Balogun, Oluwo-Keesi, Imam, Apakila, Opeji, Ariwo and Oluga.

Secondly, ten houses were randomly selected from each of the 15 sampled villages for both in-door air quality monitoring and questionnaire survey. The gasman autosampler was used to monitor the concentration of nitrogen dioxide $\left(\mathrm{NO}_{2}\right)$, sulphur dioxide $\left(\mathrm{SO}_{2}\right)$ carbon monoxide (CO), hydrogen sulphide $\left(\mathrm{H}_{2} \mathrm{~S}\right)$ and methane $\left(\mathrm{CH}_{4}\right)$. These gases are known to induce or cause respiratory disease in exposed humans and also contribute 
to the problem of global warming. These five gases were monitored thrice [morning, afternoon and evening] in replicates, in each of the villages between May and July, 2005.

In each house where air quality was monitored, a validated well-structured questionnaire was administered to elicit information on sources of energy, location of cooking points, problems encountered in energy sourcing, commonly treated health problem and the experience of some selected ailments. Respondents in this study were residents who voluntarily agreed to participate after the purpose of the research was explained to them. The total number of houses monitored for air quality and also the number of respondents' interviewed were $150 \quad[10$ respondents per village] in all. The data collected from the two sources were subjected to descriptive and inferential analyses using the statistical package for Social Sciences (SPSS version 12.0.1).

\section{Results and Discussion}

\section{Indoor air quality measurement}

The mean concentration of $\mathrm{SO}_{2}$ among the villages ranged between 0.04 and $0.51 \mathrm{ppm}$ with an overall mean value of $0.05 \mathrm{ppm}$ which is higher than the permissible limit $(0.01 \mathrm{ppm})$. Methane $\left(\mathrm{CH}_{4}\right)$ concentration monitored among the villages ranged between 0.14 and $0.22 \mathrm{ppm}$ which exceeded the limit of 0.06 ppm. In the case of $\mathrm{NO}_{2}$, the mean values ranged between 0.19 and $0.52 \mathrm{ppm}$ which were higher than the W.H.O limit of $0.06 \mathrm{ppm} . \mathrm{H}_{2} \mathrm{~S}$ had a mean concentration of $0.15(0.13-0.16)$ ppm which is equally higher than the permissible limit of $0.06 \mathrm{ppm}$. The mean of $\mathrm{CO}$ concentration $(82.5 \mathrm{ppm})$ measured among the villages was outstandingly higher than the permissible limit of 10-20 ppm. The high concentration of monitored gases agreed with the observations of Traynor, et al., (1985) and Knight et al., (1985). Smith (2009) and Mac (2009) attested to high concentration of these parameters and other pollutants in rural areas where biomass energy is the primary source of energy.

Although the concentrations of the five monitored gases were higher than the permissible limits, $\mathrm{CO}, \mathrm{H}_{2} \mathrm{~S}$ and $\mathrm{NO}_{2}$ varied significantly $(\mathrm{P}<0.05)$ among the villages at evening time while morning and afternoon showed no significant variation. There was no significant variation in the concentration of
$\mathrm{SO}_{2}$ and $\mathrm{CH}_{4}$ monitored at morning, afternoon and evening among the villages.

\section{Household survey}

The socio-demographic characteristics of the respondents (Table 3) showed that 76.0 percent were between ages 30 to 59. Common occupation of the villagers was farming (65.3\%); apart from others who engaged in hunting and selling of farm produce. The occupation characteristic portrays the communities as typical local-faming communities in western Nigeria and perhaps Africa, where many villages are "satellite" farm settlements established by town dwellers needing large expanse of land for farming purposes (Gana, 1983).

Table 4 shows that over 80 percent of the respondents depend on fuel-wood for their energy provision. Reasons for their choice of fuel-wood are closely linked to its availability at no monetary cost $(61.3 \%)$. Others claimed that fuel-wood cooks faster than kerosene. This assertion may not be unconnected with rural large-household-cooking practice where more than 15 persons may be feeding from a central cooking pot. While charcoal was very unpopular among these respondents, 22 percent used kerosene for fueling lamps. In sub-Saharan Africa and the Indian subcontinent, woodfuel is acknowledged as the main source of energy in rural communities (Chege, 1994; Madubansi and Shackleton, 2006).

Moreover, about 25 percent of the respondents located their cooking point indoor; others who claimed outdoor location of their cooking points actually have such in close proximity to the dwelling units. More than 80.0 percent of the respondents, mostly married women (69.3 $\%)$ spend an average of 8hours indoor daily. This indicates that women with their children are more exposed to the risks associated with indoor air pollution in the rural areas (Moschandreas, et al; 1981; Chege, 1994).

Table 5 shows that malaria topped the list of recently treated diseases as it affected about 50 percent of the rural dwellers. Less than two percent of the rural dweller identified cold/catarrh and cough as health problem. The prevalence of air pollution related ailments suffered by the rural dwellers were sneezing $(45.2 \%)$, followed by headache $(36.7 \%)$ and nausea (35.4\%), dizziness and eye irritation (Table 6). Most of the respondents did not consider these respiratory ailments suffered by 
them as a serious problem hence; they were not mentioned in Table 5. Health problems from air pollution are known to be subtle (Mac, 2009) since serious outcome take a fairly long latency period.

This disposition may be linked to the fact that health problems that do not impair their productivity on the farm are not often considered to be serious. Again, the respiratory diseases have become quite frequent that the respondents might have developed means of coping with or they live by them. A critical consideration of health problems suffered by these respondents showed that ailments closely associated with human exposure to air pollutants are prevalent among the respondents (Oin, et al; 1993; Frampton, et al; 1991 and Jones, 1999; Theuri, 2009). The general high concentration of $\mathrm{CO}, \mathrm{H}_{2} \mathrm{~S}, \mathrm{CH}_{4}, \mathrm{SO}_{2}$ and $\mathrm{NO}_{2}$ in the sampled houses explains the frequent experience of respiratory ailments.

Although the current study did not consider occurrence of chronic ailments among the rural dwellers, the functioning of their lungs and hearts, their exposure over a long period of time to high concentration of the monitored gases gives indication that the studied rural communities might be suffering from some chronic diseases.

\section{References}

Akanni, C.O. (1992), Aspects of Climate. In: Ogun State in Maps. In Onakomaiya, S.O., Oyesiku, Kand Jegede, J (eds.). Rex Charles Publication, Ibadan. pp 18-19.

Ayars, G. H. (1997), Biological agent and indoor air pollution. In Indoor air pollution and health Badana, E.J. and Montanaro, A.(eds.). Marcel Dekker. New York. pp 11-60. Chege, N. (1994), The Fuelwood Issue Restated. In: Energy for the household Issue 32. www.hedon.info/boilingpoint.

Carter, B. (1998), Cities and Health In: Environment Matters. An Annual Review of the World

Bank. The World Bank Group 1818 H Street, N.W. Washington, D.C 20433. pp 38- 39 Frampton, M. W., Morrow, P.E., Cox, C., Gibb, F.R., Speer, D.M., and Utell, M.J. (1991), Effects of Nitrogen dioxide exposure on pulmonary functions and airway reactivity

\section{Conclusion}

Utilization of fuel-wood as a source of energy is a major source of indoor air pollution in the study area. Apart from the fact that these gases affect human health negatively, their eventual release into the larger environment is capable of adding to the concentration of green house gases in the atmosphere.

Considering the negative consequences of indoor air pollution in rural areas, it is recommended that drastic measures be put in place so as to reduce the high level of pollution. Such measures should consider redesigning houses in rural areas to allow adequate ventilation, while cooking points should be located outside the dwelling units or separated from the dwelling units.

A sustainable alternative source of energy that is readily available should be developed for the use of rural dwellers. Biogas is prominent among the possible energy sources that could be managed at the household level. Cooking stove with efficient combustion design should be introduced into the rural communities so as to minimize the emission of pollutants during cooking process.

Environmental awareness and education should be embarked upon in the rural areas to sensitize the residents to the health problems associated with exposure to high level air pollutants within the house.

in normal humans.Am. Rev. Respir. Disorder. 143, 522-527.

Gana, J.A (1983), Rural Settlement. In A Geography of Nigeria Development $2^{\text {nd }}$ edition (eds. Oguntoyinbo, et al., 1983). Heinemann Education Pub. (Nigeria) Ltd. pp 172-174.

Gbadegesin, A.S. (1992), Vegetation. In: Ogun State in Maps. Onakomaiya, S.O, Oyesiku, K and Jegede, J (eds.). Rex Charles Publication, Ibadan. $\mathrm{p} 21$.

Godish, T. (1998), Indoor Air Pollution Control. Lewis Publishers, Florida. pp 1-2.

Goldstein, I.F., Andrews, L.R. and Hartel, D. (1988). Assessment of human exposure to nitrogen, carbon monoxide and respirable particles in New York Inner-city residences. Journal of Atmosph. Environment, 22, 2127 2139.

Jones, A.P. (1999), Indoor Air Quality and Health. Atmospher. Environm.33, 4535-4564. 
Knight, C.V., Cooper, K.R. Alberti, R.R. and Ember, L.R. (1985), Indoor Air Quality Related to wood Heaters. In: Proceedings of IAQ '86 Managing Indoor Air for Health and Energy Conservation. American Society of Heating, Refrigerating and Air Conditioning Engineers, Atlanta. pp 430-447.

Mac (2009), Indoor Air Pollution Create Problems for Rural Areas. http://www.lifeofearth.org

Madubansi, M. and Shackleton, C.M. (2006), Changes in fuelwood use and selection following electrification in the Bushbuckridge lowveld, South Africa. http://www. sciencedirect.com.

Oin, Y.H., Zhang, X.M., Jin, H.Z., Liu, Y.Q., and Fan, Z.J (1993), Effects of Indoor Air Pollution on Respiratory illness of School Children. Proceedings of the Sixth
International Conference on Indoor Air Quality. Clim. Helsinki, Finland. pp 477-482.

Sinton, J. and Weller, R.P (2003), Air Pollution Challenges in Rural China. www.wilsoncenter.org

Smith, K.R. (2009), Health impacts of household fuelwood use in developing countries, http://www.fao.org/docrep.

Theuri, D. (2009), Rural energy, stove and indoor air quality: The Kenya Experience http://www.itdg.org

Traynor, G.W., Hamilton, M., Marbury, M., and Wanner, E.U (1985), Indoor Air Pollution due to Emissions from wood-burning stoves. LBL-17854 Lawrence Berkeley Laboratory, Berkeley, C.A. pp 264-281.

WHO (1997), Health and Environment in Sustainable Development: Five years after the Earth Summit. p. 87

Table 1: Mean Concentration of $\mathrm{SO}_{2}, \mathrm{NO}_{2}, \mathrm{CO}, \mathrm{H}_{2} \mathrm{~S}$ and $\mathrm{CH}_{4}$ in rural communities

\begin{tabular}{|c|c|c|c|c|c|}
\hline Village & $\mathrm{SO}_{2}$ & $\mathrm{NO}_{2}$ & $\mathrm{CO}$ & $\mathbf{H}_{2} \mathbf{S}$ & $\mathbf{C H}_{4}$ \\
\hline Balogun & $0.050 \pm 0.006$ & $0.226 \pm 0.017$ & $85.33 \pm 4.77$ & $0.156 \pm 0.011$ & $0.155 \pm 0.010$ \\
\hline Kemta Apakila & $0.047 \pm 0.005$ & $0.191 \pm 0.008$ & $80.27 \pm 0.95$ & $0.141 \pm 0.029$ & $0.213 \pm 0.045$ \\
\hline Kinleyin & $0.050 \pm 0.003$ & $0.216 \pm 0.010$ & $84.17 \pm 1.16$ & $0.152 \pm 0.006$ & $0.149 \pm 0.008$ \\
\hline Gbagba & $0.043 \pm 0.008$ & $0.182 \pm 0.020$ & $80.50 \pm 3.74$ & $0.126 \pm 0.019$ & $0.137 \pm 0.013$ \\
\hline Aaya & $0.048 \pm 0.005$ & $0.202 \pm 0.015$ & $82.43 \pm 1.94$ & $0.150 \pm 0.009$ & $0.149 \pm 0.006$ \\
\hline Imam & $0.040 \pm 0.008$ & $0.181 \pm 0.023$ & $77.67 \pm 3.09$ & $0.133 \pm 0.008$ & $0.132 \pm 0.008$ \\
\hline Oluwo Keesi & $0.043 \pm 0.007$ & $0.199 \pm 0.024$ & $81.83 \pm 3.45$ & $0.140 \pm 0.013$ & $0.137 \pm 0.013$ \\
\hline Arowo & $0.046 \pm 0.003$ & $0.216 \pm 0.014$ & $82.17 \pm 1.82$ & $0.147 \pm 0.004$ & $0.144 \pm 0.009$ \\
\hline Osara & $0.049 \pm 0.004$ & $0.214 \pm 0.021$ & $82.10 \pm 2.81$ & $0.150 \pm 0.010$ & $0.155 \pm 0.011$ \\
\hline Opeji & $0.048 \pm 0.004$ & $0.226 \pm 0.012$ & $83.73 \pm 1.76$ & $0.154 \pm 0.007$ & $0.147 \pm 0.009$ \\
\hline Alli Iwo & $0.047 \pm 0.006$ & $0.201 \pm 0.009$ & $80.00 \pm 1.06$ & $0.148 \pm 0.006$ & $0.146 \pm 0.008$ \\
\hline Ogboja & $0.051 \pm 0.002$ & $0.224 \pm 0.001$ & $84.57 \pm 0.61$ & $0.152 \pm .0 .002$ & $0.150 \pm 0.008$ \\
\hline Apakula & $0.045 \pm 0.001$ & $0.219 \pm 0.006$ & $84.60 \pm 0.16$ & $0.148 \pm 0.005$ & $0.145 \pm 0.003$ \\
\hline Ariwo & $0.049 \pm 0.005$ & $0.232 \pm 0.011$ & $84.33 \pm 1.27$ & $0.152 \pm 0.007$ & $0.152 \pm 0.007$ \\
\hline Oluga & $0.048 \pm 0.004$ & $0.231 \pm 0.005$ & $83.77 \pm 1.03$ & $0.146 \pm 0.004$ & $0.150 \pm 0.005$ \\
\hline Overall mean & $0.050 \pm 0.006$ & $0.210 \pm 0.013$ & $82.50 \pm 1.98$ & $0.147 \pm 0.009$ & $0.156 \pm 0.010$ \\
\hline Permissible limit & $0.01-0.1$ & $0.04-0.06$ & $10.0-20.0$ & 0.06 & 0.06 \\
\hline
\end{tabular}

Table 2: ANOVA result of the selected pollutants across the rural communities

\begin{tabular}{lrllrr}
\hline Parameter & F - value Sig. Level & Parameter & F - value & Sig.Level \\
\hline $\mathrm{SO}_{2}$ Morning & 0.945 & 0.51 & $\mathrm{NO}_{2}$ Morning & 1.100 & 0.36 \\
$\mathrm{SO}_{2}$ Afternoon & 0.960 & 0.49 & $\mathrm{NO}_{2}$ Afternoon & 1.438 & 0.14 \\
$\mathrm{SO}_{2}$ Evening & 3.478 & 0.66 & $\mathrm{NO}_{2}$ Evening & 2.698 & 0.002 \\
$\mathrm{SO}_{2}$ Overall & 0.662 & 0.79 & $\mathrm{NO}_{2}$ Overall & 0.914 & 0.55 \\
$\mathrm{CO}$ Morning & 0.849 & 0.61 & $\mathrm{CH}_{4}$ Morning & 0.860 & 0.60 \\
$\mathrm{CO}$ Afternoon & 0.939 & 0.52 & $\mathrm{CH}_{4}$ Afternoon & 0.989 & 0.47 \\
$\mathrm{CO}$ Evening & 2.470 & 0.04 & $\mathrm{CH}_{4}$ Evening & 1.465 & 0.13 \\
$\mathrm{CO}$ Overall & 1.930 & 0.06 & $\mathrm{CH}_{4}$ Overall & 1.501 & 0.17 \\
$\mathrm{H}_{2} \mathrm{~S}$ Morning & 1.027 & 0.43 & & & \\
$\mathrm{H}_{2} \mathrm{~S}$ Afternoon & 0.695 & 0.78 & & & \\
$\mathrm{H}_{2} \mathrm{~S}$ Evening & 2.453 & 0.04 & & & \\
$\mathrm{H}_{2} \mathrm{~S}$ Overall & 1.295 & 0.26 & & & \\
\hline
\end{tabular}


Table 3: Socio-demographic characteristics of sampled rural dwellers

\begin{tabular}{lcc}
\hline Demographic Characteristics & No. of Respondents & Percent \\
\hline Age-group & 22 & 14.7 \\
$20-29$ years & 33 & 22.0 \\
$30-39$ years & 49 & 32.7 \\
$40-49$ years & 32 & 21.3 \\
$50-59$ years & 14 & 9.3 \\
60 years and above & $\mathbf{1 5 0}$ & $\mathbf{1 0 0 . 0}$ \\
Total & & \\
Sex & 46 & 30.7 \\
Male & 104 & 69.3 \\
Female & $\mathbf{1 5 0}$ & $\mathbf{1 0 0 . 0}$ \\
Total & & \\
Marital status & 15 & 10.0 \\
Single & 127 & 84.7 \\
Married & 8 & 5.3 \\
Others & $\mathbf{1 5 0}$ & $\mathbf{1 0 0 . 0}$ \\
Total & & \\
Occupation & 98 & 65.3 \\
Farmers & 37 & 24.7 \\
Traders & 8 & 5.3 \\
Hunters & 7 & 4.7 \\
Others & $\mathbf{1 5 0}$ & $\mathbf{1 0 0 . 0}$ \\
Total & & \\
\hline
\end{tabular}

Table 4: Cooking energy sources and exposure to indoor pollutants

\begin{tabular}{lcc}
\hline Energy sourcing & No. of Respondents & Percent \\
\hline Energy source & & \\
Fuel wood & 125 & 83.3 \\
Charcoal & 3 & 2.0 \\
Kerosene & 22 & 14.7 \\
Total & $\mathbf{1 5 0}$ & $\mathbf{1 0 0 . 0}$ \\
Reason for choice & & \\
Fuel wood is easy to source & 35 & 23.3 \\
Fuel wood is readily available & 22 & 14.7 \\
Fuel wood is cheap & 35 & 23.3 \\
Fuel wood cooks faster & 27 & 18.0 \\
Kerosene is scarce & 4 & 2.7 \\
Kerosene is neat and easier to use & 14 & 8.7 \\
Others & 5 & 3.5 \\
Total & $\mathbf{1 5 0}$ & $\mathbf{1 0 0 . 0}$ \\
Location of cooking point & & \\
Indoor & 37 & 24.7 \\
Outdoor & 113 & 75.3 \\
Total & $\mathbf{1 5 0}$ & $\mathbf{1 0 0 . 0}$ \\
& & \\
Hours spent indoor & & 14.0 \\
Below 6 hours & 21 & 61.3 \\
6 - 10 hours & 92 & 24.7 \\
Above 10 hours & 37 & $\mathbf{1 0 0 . 0}$ \\
Total & $\mathbf{1 5 0}$ &
\end{tabular}


Table 5: Health problems treated recently by the rural dwellers

\begin{tabular}{lcc}
\hline Health problem & No. of Respondents & Percent \\
\hline Malaria & 93 & 49.7 \\
Typhoid fever & 12 & 6.4 \\
Body pain & 38 & 20.3 \\
Stomach ache & 5 & 2.7 \\
Yellow fever & 5 & 2.7 \\
Head ache/ Fever & 16 & 8.6 \\
Cold/Catarrh/cough & 15 & 1.6 \\
Others & 3 & 1.6 \\
Total & 187 & 100.0 \\
\end{tabular}

* Multiple responses

Table 6: Air pollution related ailments and among sampled rural dwellers

\begin{tabular}{lclc}
\hline Health problem & Frequently & Occasionally & Rarely \\
\hline Eye irritation & $35(25.4)$ & $76(55.1)$ & $27(19.6)$ \\
Dry throat & $15(12.7)$ & $62(52.5)$ & $41(34.7)$ \\
Head ache & $51(36.7)$ & $73(52.5)$ & $15(10.8)$ \\
Sneezing & $66(45.2)$ & $71(48.6)$ & $9(6.2)$ \\
S kin irritation & $14(12.6)$ & $59(53.1)$ & $38(34.2)$ \\
Shortness of breath & $7(10.0)$ & $29(41.4)$ & $34(48.5)$ \\
Cough & $28(24.3)$ & $55(47.8)$ & $32(27.8)$ \\
Dizziness & $47(33.3)$ & $74(52.3)$ & $20(14.2)$ \\
Nausea & $51(35.4)$ & $75(52.1)$ & $18(12.5)$ \\
Catarrh & $36(25.9)$ & $93(66.9)$ & $10(7.2)$
\end{tabular}

* Multiple responses 


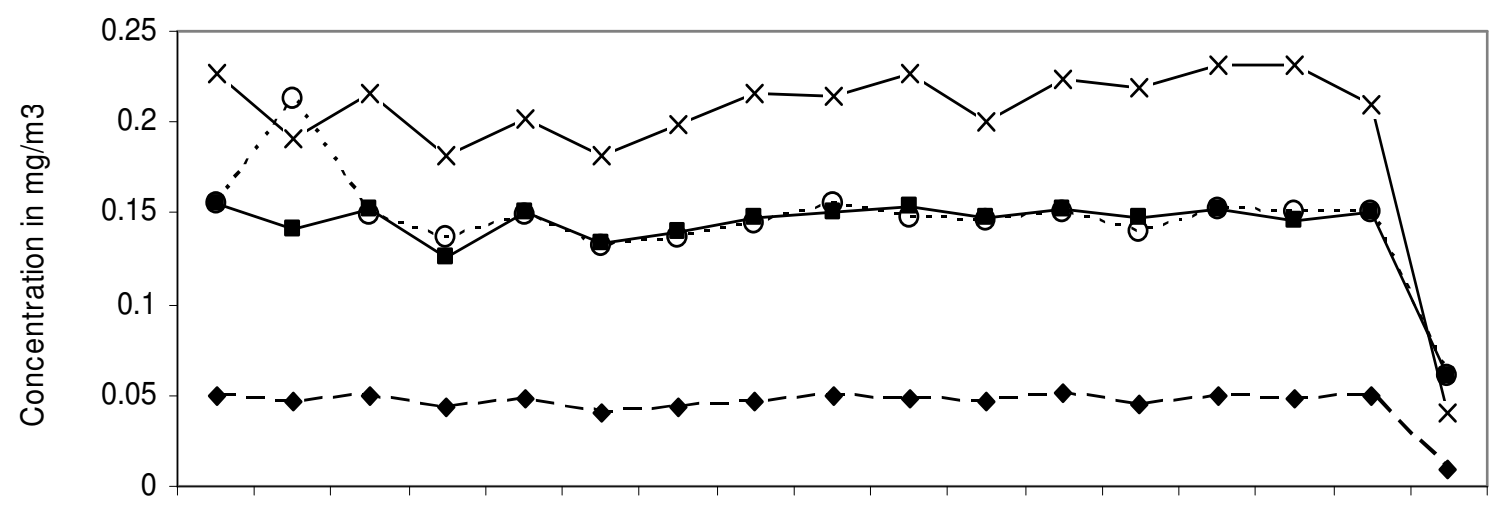

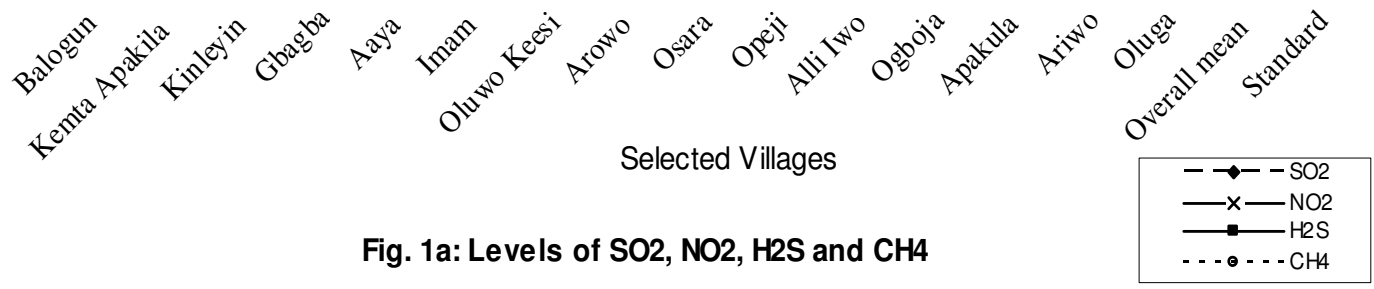

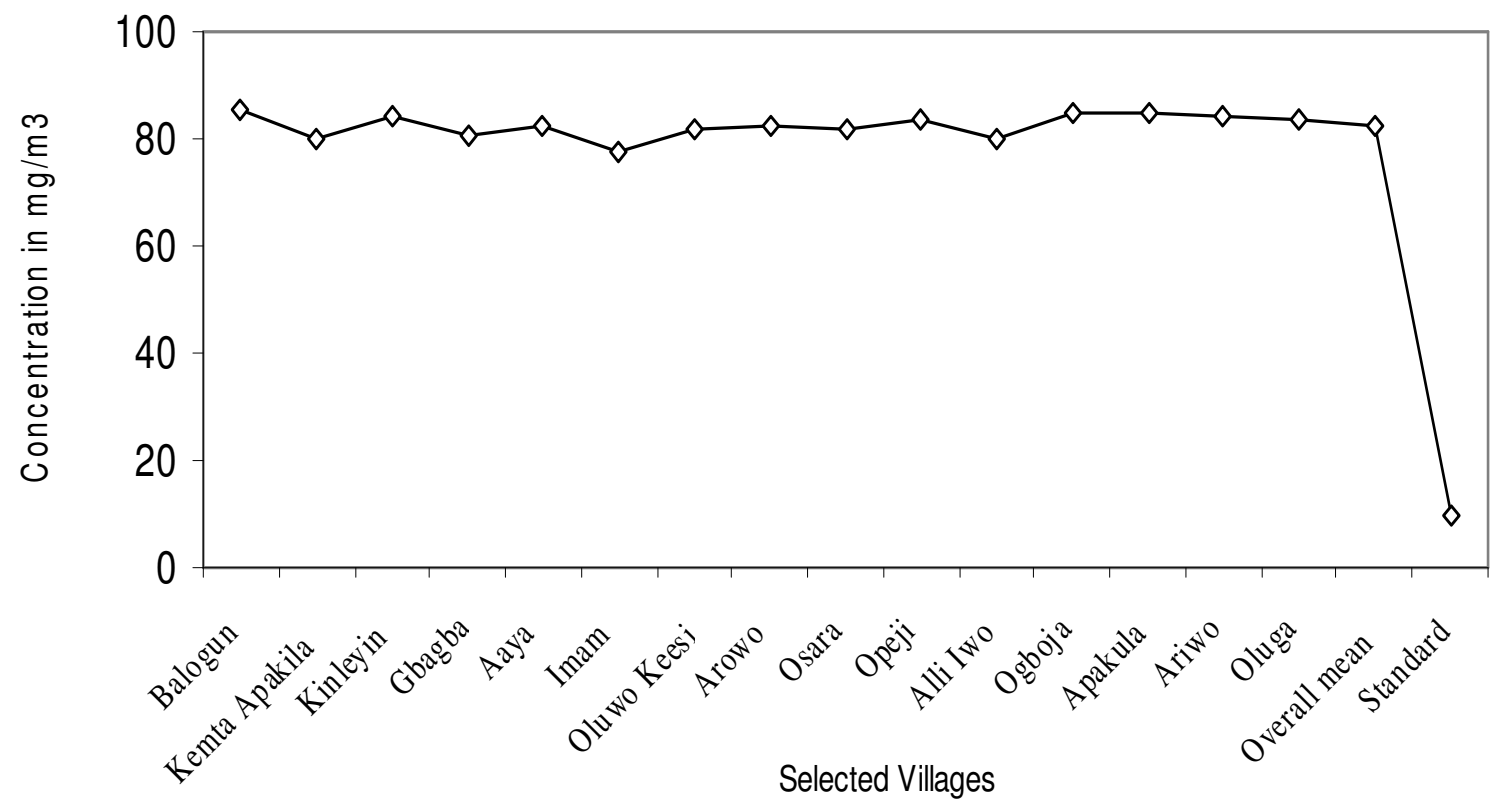

Fig. 1b: Level of CO 